\title{
Lost Vision
}

Lloyd M. Basham, Texas A\&M University-Commerce, USA

\begin{abstract}
This case is to be used as an understanding of the causalities that result from the disarray of future direction, impeding chaos and dysfunctional status to an organization when its "Vision" is lost. The case presents the financial impact when the impetus of a strategy implementation incurs a major disruption due to the loss of its inspirational and transformational leader. The joint venture had completed its internal structuring, communicated internally its mission and product and services, acquired and/or spent many millions of dollars in operational and capital infra-structure prior to its premier into the marketplace. The case describes the environment of disillusion, political in-fighting, and personal and selfish objectives that resulted in the death of the joint venture. Analysis of the case should address the organizational and managerial behavior that should have been the practical application and situation in order for the continual implementation of the organization and benefit to the market place and all stakeholders.
\end{abstract}

Keywords: Transformational Leadership; Power; Destructive Political Alliances; Organization and Managerial Behavior; Negative Impact to all Stakeholders

\section{SITUATION}

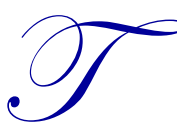

he day (in late October) began with the notification of all executives (by email) for the Network Solutions Joint Venture to meet in Nashville tomorrow at 8:00 a.m. at the site conference room. No agenda was sent nor was any explanation as to what the meeting was about. You have your administrative assistant to make early evening flight arrangements with reservations at the local hotel that is adjacent to the headquarters site. Within the hour you have been contacted by two other executives questioning as to what the meeting is about? Since the notification came from the Executive Vice President of the parent company, Networks, and not the President of the joint venture, a consensus amongst the three of you was that the meeting was about the President of the Joint Venture. Your current day's agenda included a scheduled meeting with local call center managers which would include a conference call with the other two regional call centers; one in California and the other in Connecticut. You decide to continue with the meeting with the call centers. The purpose of the call centers meeting was to discuss issues related to overlapping of territories and identification of which customers would be considered "corporate accounts" and which call centers would handle these corporate customers. Other issues to discuss were which company policies (since this was a joint venture and contained employees from both companies in the venture) would be applicable; and especially, high on the priority list, was the administration of holidays with the upcoming Thanksgiving and Christmas periods.

\section{BACKGROUND INFORMATION}

Two legal entities, Networks headquartered in the U.S. (but subsidiary of a foreign country entity) and Communications Solutions, (subsidiary of a U.S. entity) have joined in a Joint Venture with a scope within the United States. The joint venture is the vision of a Senior Vice President of Networks. He had approached the President of Communications Solutions (parent company) at a trade show in Georgia with the idea of forming a joint venture between the two parent companies. After many discussions and subsequent presentations and finally each respective Board of Directors approval the Joint Venture was formed. The name of the Joint Venture would be Network Solutions.

\footnotetext{
${ }^{1}$ Situations, incidents and information are factual; however, companies and organizational names are fictitious and names of participants have been omitted.
} 
Each respective company, Networks and Communications Solutions, within the Joint Venture Company had the following "influences:"

1. Large scale communications technological products and services sold primarily to large public and private corporations.

2. Both had a ranking of either a Fortune 100 U.S. company or Global 50 Fortune company.

3. There was "some overlapping" of same products and services but for the most part each company was somewhat unique in either their products and services capabilities and/or the delivery of their products and services.

4. Territory was the continent United States.

5. Applicable Regulatory coverage was the United States.

Each respective company, Networks and Communications Solutions, within the Joint Venture would have the following components:

- Specific identified employees from both parent companies would become (structure wise) employees of the joint venture but would retain their employee status as employees of their respective companies.

- With very few exceptions; there would not be any relocation of employees including the operational executives.

- Each parent company would "contribute" their respective "assets" to the joint venture.

- Financially, the joint venture would have its Operational Profit and Loss and Balance Sheet, but its components would be separated and "rolled" back into their respective parent companies for legal entity reporting and tax filing.

- Operational reporting by the executive teams would require two direct lines of reporting back to the respective parent companies.

- Employees, including service personnel, would be located throughout the United States with representation in all 50 states.

\section{STRUCTURE OF JOINT VENTURE}

President- Individual who presented the vision. Dual direct line of reporting to Executive Vice Presidents of each parent company. Legal entity employee of Networks. Physically located in Nashville, Tennessee.

Vice President of Marketing. Dual direct line of reporting to President of Joint Venture and Executive Vice President of Marketing of Networks. Physically located in Toronto, Canada. (The only external hire).

West Vice President of Operations. Dual direct line of reporting to President of Joint Venture and Executive Vice President of Networks. Physically located in San Mateo, California (Son of member of Board of Directors for Networks).

East Vice President of Operations. Dual direct line of reporting to President of Joint Venture and Executive Vice President of Networks. Physically located in Washington, D.C.

Controller. Actually, three lines of reporting which included President of Joint Venture and Controller of Networks and Controller of Communications Solutions. Located in Richardson, Texas.

Vice President of Services. Dual direct line of reporting to President of Joint Venture and Executive Vice President of Communication Services. Physically located in Richardson, Texas- See clarification below.

Vice President of Manufacturing. Dual direct line of reporting to President of Joint Venture and Executive Vice President of Communication Services. Physically located in Tempe, Arizona.

Vice President of Personnel. Dual line of reporting to President of Joint Venture and Executive Vice President of Communication Services. Physically located in Tempe, Arizona. 
[You have the title of Vice President of Services within the joint venture, and Corporate Senior Vice President of the operational and legal entity that is one party to the Joint Venture-Communications.]

\section{ACTIVITY AND STATUS OF JOINT VENTURE PRIOR TO ANNOUNCEMENT}

\section{Generalization}

Joint Venture had been given birth on January 1st of the year. The President (with the Vision) was the "employee" number 1 . The above mentioned executives had been sourced from their respective legal entity association as stated above with the exception of the Vice President of Marketing who was an external hire. The first meeting of the new Joint Venture has taken place in Washington, D.C. just prior to the Christmas holidays. From the questions, comments and statements, it became very noticeable that the two Vice Presidents of Operations from the West and East were not very happy with this arrangement or "assignment."

Instead of being proactive in the meeting as to how we could "mesh" these two cultures of people and begin structuring the venture, too much of the time was spent questioning as to how this is going to "work." Regardless, a video was prepared introducing each of the executives (with introductory background) which would be distributed to all employees and personally presented as a road show in January to all of the major locations that had over 100 people at that particular location.

During the road show and the introduction and explanation of the joint venture, personnel were given the opportunity to ask questions regarding what impact this had on them. Key points and emphasis were made of the organizational charts which were very detailed. Expectedly, the primary concern was tenure, status, job grade, and benefits and whether they would continue to have employment. After these concerns were addressed with the explanation that their employment would continue and their status would remain with their prior association with all benefits, tenure, job grade, etc., remaining unchanged; it was determined that the "roll out" had gone well.

The video and road show, including all travel expenses, incurred approx. $\$ 1,100,000$. This included the leasing of large auditorium rooms which could accommodate, not only local employees, but all surrounding employees, who could travel by car to the presentation.

The next activity included the changing of the logo and the repainting and remarking of all service vehicles as well as "company" (new joint venture name) vehicles. This also included all signage and building identification. This expense incurred about $\$ 750,000$ dollars.

Next was the printing of new marketing collateral, which included stationary, letterheads and business cards. This activity was about $\$ 500,000$.

All other expenses associated with the multiple reporting of start-up to all respective dual lines of reporting as well, and operational travel with meetings due to the executive being located in six different geographic locations had by the date of the email announcement amounted to another one million dollars.

Each operational meeting required numerous amounts of time as the results of the West and East executives became "hostile" and/or negative to the joint venture arrangement and reluctant to relinquish any of their previous operational authority, personnel and/or daily operations. In many cases it had been reported that the West and East had communicated in town hall meetings to "just be patient as we will eventually go back to our original structure and the Joint Venture will cease to exist." Employees had communicated to their respective managers and those mangers had come to their respective executives with the following question - "exactly who do I report to, who will do my performance reviews, and who will be responsible for my level of salary increases."

\section{MARKETING}

The marketplace had accepted the name change and the marketing activity had been very successful with "getting the name out." Large corporate accounts had accepted the name change as there had not been any disruption to ongoing business. In fact, half a dozen new corporate accounts had been added because now products and services that they had needed was now available from one "source." 


\section{SALES}

Sales and revenue activity had continued at the same pace as before. The sales force was not encountering any push back as each sales force was continuing to present the same products and services as before. The only thing that had changed was the name of the "company." Backlog was growing and there had not been any significant cancellation of orders. If an order had been cancelled; there was not any indication that it was as a result of the name change or the "combining of the two companies."

\section{ADMINISTRATIVE}

Other than approximately 60 days of transition confusion and disruption; the purchasing, distribution and invoicing activity had settled down and functions were operating at quality levels as before the formation of the venture.

\section{FIELD}

Installations, de-installations, replacements, and contractual maintenance never did "skip a beat" and there was not any internal confusion amongst the field personnel nor any major complaints from customers on the field personnel performance of their activities.

The fact that the transition into a "new" entity was achieved without major problems by the major functions of the entity could be attested to the professionalism and caliber of the rank and file personnel. Managers and supervisors worked diligently and genuinely to achieve the objective to ensure the transition went according to plan.

\section{ISSUE}

The meeting in Nashville did not begin on time, as a matter of fact, it was almost two hours late. When it finally began, the individual, and only individual that entered the room was the Networks legal entity Executive Vice President. Very noticeable was the absence of the Joint Venture President. The Executive Vice President stated the President of Joint Venture (who had been recruited by a major competitor) had already departed the premises. When asked who might be the interim and what impact does this have on the Joint Venture, the Executive Vice President simply said that future announcements would be forth coming and immediately left the room. It was discovered later in the day that the Executive Vice President of the legal entity Networks had met for dinner the night before with the West and East Operational Vice Presidents.

\section{QUESTION}

After analyzing the situation, what should have been the organizational and managerial behavior of the executives during the first 9 months of start-up prior to the announcement of the President departing for a position with a competitor? Also, during this same time period what should have been the leadership acumen of the President of the Joint Venture prior to his departure? What could have been the direction given to the executives by the Executive Vice President for immediate action to take after the announcement? By the lack of a communicative action or transition plan, what did this convey to the executives? And what should have been the executive's managerial behavior and leadership after the announcement? List and explain the impact to the stakeholders of the organization. Give justifications and reasons for your analysis and answers.

\section{INSTRUCTIONS}

Read and analyze the above case.

Answer the above questions utilizing external research for the keywords in the Abstract. Also charts, graphs and illustrations would be very helpful in supporting your decision and position. 


\section{INTENDED COURSE(S), LEVEL, AND TOPIC(S)}

This case is intended to be used in a Management or Executive MBA course at the graduate level. The case could be used in the latter part in the course and/or as the capstone case or exam. The case provides opportunities for class discussion about need for understanding the climate and atmosphere related to key executive changes and understanding the impact upon the organization's culture and direction on the enterprise.

\section{OBJECTIVES}

- Be able to recognize, analyze and demonstrate the understanding of values, power, and influence relating to organizational culture, change, and decision-making in global contexts.

\section{AUTHOR BIOGRAPHY}

Dr. Lloyd M. Basham is an instructor of management in the College of Business at Texas A\&M UniversityCommerce. He holds the degrees of BBA, MBA, M.A. and Ed. D. His practical experiences are as an early corporate America executive retiree with 35 years of corporate background. These associations were with Fortune 200 firms in the computer/telecommunications and security risk and financial services industries in various executive positions both in financial and operational capacities. As an instructor with TAMU-Commerce since his retirement in 2002, he has taught both on premise and online undergraduate and graduate classes.

\section{SUGGESTED REFERENCES}

Brown, A.D. 1997. Narcissism, identity, and legitimacy. Academy of Management Review, 22: 643-686.

Howell, J.M., \& Shamir, B. 2005. The role of followers in the charismatic leadership process: Relationships and their consequences. Academy of Management Review, 30: 96-112.

King, G. 2007. Narcissism and effect crisis management. A review of potential problems and pitfalls. Journal of Contingencies and Crisis Management, 15: 183-193.

Wales, W.J., Patel, P.C. \& Lumpkin, G.T. 2013. In pursuit of greatness: CEO narcissism, entrepreneurial orientation, and firm performance variance. Journal of Management Studies, 50:1041-106. 


\section{TEACHING OBJECTIVES}

Students should be able to:

- Present an answer to the question "Does a Transformational Leader" also have the traits to implement the vision?

- Understand the impact to the organization when the visionary of the organization departs (for whatever reasons) and the subordinates either do not or have not "brought into" the vision and strategy.

- Recognize and be able to outline the management practices necessary in a situation where subordinates have either a nepotism, power or political alliance with the upper hierarchy of the organization.

- Analysis should include management concepts to counteract group and individual negative behavior that does not contribute to a productive environment.

- Analysis should address the critical need for "staffing" personnel who embrace the vision and strategy of the organization.

\section{TEACHING NOTES}

Can be provided by contacting lloyd.basham@tamuc.edu 